\title{
From management to prevention: the new cure for sports concussion
}

\author{
John Batten, ${ }^{1}$ Adam John White, ${ }^{1}$ Eric Anderson, ${ }^{1}$ \\ Rachael Bullingham²
}

\section{INTRODUCTION}

A recent BJSM editorial argued that 'turning people into couch potatoes is not the cure for sports concussion'. ${ }^{1}$ Specifically, it was noted how heightened anxiety over sports concussion has caused participation levels to fall; that concussions are common in contact sports; and that there remains a need for the development of specific concussion management protocols targeted at each level of the game. In this response, the evidence to support each of these contentions is examined. A case for directing attention away from concussion management and towards the prevention of concussions in sport is also stated.

\section{CONCUSSION AS A BARRIER TO PHYSICAL ACTIVITY}

In the UK, as little as $6 \%$ of men and $4 \%$ of women, aged 16 years or over, meet the recommended government guidelines for physical activity. ${ }^{2}$ Such statistics support the argument that the UK as a whole is becoming dangerously inactive. Indeed, insufficient physical activity leads to $\sim 3$ million deaths (globally) per year. ${ }^{3}$ Although heightened anxiety over concussion has likely reduced participation in contact sports, there remain a number of more salient barriers (eg, time, money, facilities, etc) to the adoption of a physically active lifestyle. It is also unlikely that sport is the answer to the current physical inactivity pandemic. Instead, low-intensity physical activities (ie, walking) will likely provide a much more viable means to reduce sedentary time and increase physical activity levels on a day-to-day basis.

\section{RATES OF CONCUSSION}

There is much discussion about the negative health implications of concussion. ${ }^{4}$ Yet, while concussion is considered commonplace in sport, there remains a lack of

\footnotetext{
${ }^{1}$ Department of Sport and Exercise, University of Winchester, Winchester, Hampshire, UK; ${ }^{2}$ Institute of Sport and Exercise, University of Worcester, Worcester, Worcestershire, UK

Correspondence to John Batten, Department of Sport and Exercise, University of Winchester, Winchester, Hampshire SO22 4NR, UK; John.Batten@winchester.ac.uk
}

comprehensive data that are valid and reliable on the prevalence of concussion in contact sports, such as rugby. ${ }^{5}$ In particular, epidemiological data have not been routinely collected, making it difficult to offer a representative picture of the problem of concussion. Head trauma is also difficult to assess and diagnoseespecially by non-medical professionalsmeaning many mild traumatic brain injuries go unreported. Thus, the current lack of data on the link between concussion and participation in contact sports is often reported as a lack of problem rather than simply insufficient evidence. ${ }^{4}$ Unfortunately, this will remain a problem as long as there are no requirements for schools, hospitals and/or governing bodies to collect or report injury data. ${ }^{6}$

\section{CONCUSSION MANAGEMENT: \\ INITIATIVES AND EDUCATION}

National Governing Bodies in the UK have not been silent about concussion in sport. Exemplifying this, the Football Association recently released guidelines on return to play protocols for participants who have a suspected concussion. However, the Rugby Football Union leads the way regarding concussion-related initiatives in England. Specifically, their online HEADCASE training module aims to educate stakeholders (eg, coaches, match officials, teachers, etc) about concussion and how best to manage a person who is suspected of having a concussion, through its 'recognise, remove, recover, return' message. This is, of course, progress on the management of injured athletes. Yet, concerns have been raised about the uptake and effectiveness of such education initiatives. For instance, data collected by the Oxfordshire Rugby Football Schools Union in October 2015, found that only $14 \%$ of state school physical education teachers, who frequently deliver rugby, had received any training on the management of concussion. ${ }^{7}$ Additionally, unlike that of its New Zealand equivalent, RugbySmart, there is no requirement for coaches or referees to annually complete the HEADCASE training; meaning key stakeholders may not always have the required knowledge and skills to effectively recognise and manage injured athletes. ${ }^{8}$
PREVENTING CONCUSSION IN SPORT

Current strategies for concussion in sport focus on education initiatives, aimed at improving the management of injured players (ie, secondary prevention). The recently published guidelines for concussion recognition and management for all sports and activities in Scotland is one key example of this. However, given the documented severity of the short-term and long-term consequences of concussion (eg, chronic traumatic encephalopathy), rather than the focus on management, perhaps attention should now be directed towards preventing participants from becoming injured in the first place (ie, primary prevention). Indeed, moving the debate from recognising concussed players and the tertiary care available, to one where sport is made structurally safer, is the likely next step. For instance, rugby could be made structurally safer for children by playing touch (instead of contact) rugby in schools. Concurrently, research and interventions could (further) examine the efficacy of limiting tackle exposure during training and competition, changing the definition of a legal tackle, weightmatched/size-matched groupings (biobanding), as well as annual, mandatory coach education, on injury risk in club rugby. Such discussions could help to reduce anxiety over concussion, while simultaneously encouraging the adoption of a physically active lifestyle through sports that are safer to participate in. Although unlikely to solve the current physical inactivity pandemic, making sport more accessible and structurally safer will be beneficial to the health of all involved.

Twitter Follow John Batten @JBatz85, Adam White @AdJWhite, Eric Anderson @EricAndersonPhD, and Rachael Bullingham @bulrac

Competing interests None declared.

Provenance and peer review Not commissioned; externally peer reviewed.

To cite Batten J, White AJ, Anderson E, et al. Br J Sports Med Published Online First: [please include Day Month Year] doi:10.1136/bjsports-2015-095949

Accepted 1 May 2016

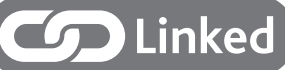

- http://dx.doi.org/10.1136/bjsports-2015-095393

Br J Sports Med 2016;0:1-2.

doi:10.1136/bjsports-2015-095949

\section{REFERENCES}

1 Calderwood C, Murray AD, Stewart W. Turning people into couch potatoes is not the cure for sports concussion. Br J Sports Med 2016;50:200-1. 


\section{Editorial}

2 Health and Social Care Information Centre. Statistics on Obesity, Physical Activity and Diet: England 2014. 2014. http://www.hscic.gov.uk/catalogue/PUB13648/ Obes-phys-acti-diet-eng-2014-rep.pdf (accessed 16 Dec 2015).

3 World Health Organization. Global Status Report of Non-Communicable Diseases 2014. 2014. http://apps. who.int/iris/bitstream/10665/148114/1/978924156 4854_eng.pdf?ua=1 (accessed 21 Jan 2015).
4 Pollock AM. Tackling rugby: what every parent should know about injuries. London: Verso, 2014.

5 Freitag A, Kirkwood G, Pollock AM. Rugby injury surveillance and prevention programmes: are they effective? BMJ 2015;350:h1587.

6 Kirkwood G, Parekh N, Ofori-Asenso R, et al. Concussion in youth Rugby Union and Rugby League: a systematic review. Br J Sports Med 2015;49: 506-10.
7 Oxfordshire Rugby Football Schools Union. Training Audit October 2015 [online]. 2015. http://www. oxonrugbyschools.co.uk/governance.php (accessed 25 Feb 2016)

8 Gianotti SM, Quarrie KL, Hume PA. Evaluation of RugbySmart: a Rugby Union community injury prevention programme. J Sci Med Sport 2009;12:371-5. 


\section{BISM From management to prevention: the new cure for sports concussion}

John Batten, Adam John White, Eric Anderson and Rachael Bullingham

Br J Sports Med published online May 23, 2016

Updated information and services can be found at:

http://bjsm.bmj.com/content/early/2016/05/23/bjsports-2015-095949

\section{These include:}

References This article cites 4 articles, 3 of which you can access for free at: http://bjsm.bmj.com/content/early/2016/05/23/bjsports-2015-095949 \#BIBL

Email alerting service

Receive free email alerts when new articles cite this article. Sign up in the box at the top right corner of the online article.

\section{Notes}

To request permissions go to:

http://group.bmj.com/group/rights-licensing/permissions

To order reprints go to:

http://journals.bmj.com/cgi/reprintform

To subscribe to BMJ go to:

http://group.bmj.com/subscribe/ 